\title{
Oxidative Processes of Desulfurization of Liquid Fuels
}

\author{
J.M. Campos-Martin*, M.C. Capel-Sanchez, P. Perez-Presas, J.L.G. Fierro \\ Instituto de Catálisis y Petroleoquímica, CSIC, Marie Curie 2, Cantoblanco, E-28049 Madrid, \\ Spain. http://www.icp.csic.es/eac/
}

*To whom correspondence should be addressed: Jose M. Campos-Martin, e-mail: j.m.campos@icp.csic.es, Phone: +34 915854948, FAX: +34 915854760

Short title: ODS processes of liquid fuels

\begin{abstract}
Environmental concerns have driven the need to remove sulfur-containing compounds from light oil. As the oxidative desulfurization is conducted under very mild reaction conditions, much attention has been recently devoted to this process. In this contribution, the developments in selective removal of organosulfur compounds present in liquid fuels via oxidative desulfurization, including both the chemical oxidation and biodesulfurization, are reviewed. At the end of each section, a brief account of the research directions needed in this field is also included.
\end{abstract}

Keywords: Oxidative Desulfurization, Biodesulfurization, Liquid Phase, Catalysis, Clean Fuels, Selective Oxidation

\section{Introduction}

Liquid fuels contain a large variety of sulfur compounds (thiols, sulfides, disulfides and thiophenes), which generate $\mathrm{SO}_{2}$ and airborne particulate emissions during combustion. Therefore, desulfurization of light oil is extremely important in the petroleum-processing industry. Several processes have been proposed in the past to deal with the problem of removing these compounds from light oil. The most important and common industrial process is that of treating the fuel under high temperatures and high pressures with hydrogen. This process is called hydrodesulfurization (HDS) and has received extensive attention since its discovery in 1930's. Literature describing this technology is tremendous, 
amounting to thousands of patents and scientific and engineering papers. ${ }^{1-4}$ HDS is a process in which light oil is heated, mixed with hydrogen, and fed to a reactor packed with a pelleted catalyst. Temperatures in the reactor typically range from 300 to $380{ }^{\circ} \mathrm{C}$. At these temperatures, some or all of the feed is vaporized, depending on the boiling range of the feed and the pressure in the unit. For heavier feeds it is common for the majority of the feed to be liquid. Reaction pressures range from as low as 15 to as high as 90 bar depending on the difficulty of removing the sulfur. ${ }^{4}$ In the production of light oil such as diesel or jet fuel, pressures higher than 30 bar are commonly used. ${ }^{2}$ In the earlier processes the feed and hydrogen mixture flow downward through the reactor, passing around and through the particulate catalyst, however in newer reactor configurations hydrogen flows upward from the bottom of the reactor (Synsat process). ${ }^{4}$ Upon leaving the reactor, the mixture of treated fuel and hydrogen flows through a series of mechanical devices to separate and recycle the hydrogen, remove the $\mathrm{H}_{2} \mathrm{~S}$ generated in the reaction, and recover the desulfurized product. HDS catalysts slowly lose activity during the operation, and must be removed and replaced after approximately two years of on-stream operation. As used in large integrated refineries, HDS is very effective and relatively inexpensive. However, the HDS is limited in treating benzothiophenes (BTs) and dibenzothiophenes (DBTs), especially DBTs having alkyl substituents on their 4 and/or 6 positions (Scheme 1). ${ }^{1-3}$ The production of light oil, with very low levels of sulfur-containing compounds, therefore requires inevitably the application of severe operating conditions i.e., very low space velocities, high temperatures and high pressures, as well as the use of highly active catalysts. ${ }^{1-4}$ An alternative process, able to be operated under moderate conditions and without requirements for $\mathrm{H}_{2}$ and catalysts, is therefore nowadays required. ${ }^{1,2}$

The organic sulfur compounds are divided in two groups: A portion that can be removed by cost-effective procedures such as HDS, and the second part, which is recalcitrant. In order to meet the ultra-low sulfur content regulations, the refractory part should also be desulfurized. ${ }^{4}$ Hydrodesulfurization is able to remove the refractory sulfur; however, for these compounds, the process is very expensive and it is performed under very high temperature and pressure conditions. ${ }^{1}$ Considering the growing trend of fuel consumption and exploiting petroleum resources, the remaining part of petroleum is more viscous and has a high sulfur content whose desulfurization will make the final desulfurized fuel product even more expensive. ${ }^{2}$ Taking advantage of an efficient mild desulfurization process will provide several benefits. It lowers the final fuel price, economizes the 
desulfurization energy consumption and produces lower amounts of pollutants. Removing sulfur by alternative technologies is one of the approaches that can potentially be used after the HDS unit in near future and replace HDS in the distant future.

\section{Oxydesulfurization (ODS) Process}

Oxidative desulfurization (ODS) has been considered as a further new technology for deep desulfurization of light oil. This desulfurization process includes two stages: (i), oxidation in a first step; and (ii), liquid extraction at the end. It is evident that the greatest advantages of the ODS process are low reaction temperature and pressure, and that expensive hydrogen is not used in the process. Another feature of ODS is that the refractory S-containing compounds in ODS are easily converted by oxidation. Therefore, ODS has great potential to be a complementary process to traditional HDS for producing deeply desulfurized light oil.

\subsection{General description}

Sulfur-containing compounds are oxidized using a selective oxidant to form compounds that can be preferentially extracted from light oil due to their increased relative polarity. Such oxidants include peroxy organic acids, hydroperoxides, nitrogen oxides, peroxy salts and ozone, etc. and such oxidants can donate oxygen atoms to the sulfur in mercaptans (thiols), sulfides, disulfides and thiophenes to form sulfoxides or sulfones (see Scheme 2). Oxidation is accomplished by contacting an oxidant with light oil under optimum conditions and continuing the reaction until the oxidized S-containing compounds are formed. Then the reaction is stopped before the oxidant attacks other, less reactive, light oil components, or the other components of the light oil cannot be oxidized under such conditions. The oxidant can then be regenerated for re-use. Washing, extraction and chemical post-treatment can remove any unused oxidant that remains in the light oil (Scheme 3). The oxidized compounds can be extracted from the light oil by contacting oxidized light oil with a nonmiscible solvent. This solvent is selective for the relatively polar oxidized S-containing compounds. The oxidized compounds and solvent are separated from the light oil by decantation. The light oil is water washed to recover any traces of dissolved extraction solvent and polished using other methods, such as by absorption using silica gel and alumina. The extraction solvent is separated from the mixture of solvent and oxidized compounds by a simple distillation for recycling. By following these steps, the highest 
amount of undesirable compounds is extracted from the fuel while doing the least amount of damage to the end product. In many cases the process improves the fuel quality as well.

The desulfurization reactivity of actual light oils, such as straight-run light gas oil (LGO), commercial light oil (CLO), and light cycle oil (LCO), of differing sulfur and aromatic concentrations, was studied using the oxidant system $\mathrm{H}_{2} \mathrm{O}_{2}$ and acetic acid (AcOH). The desulfurization efficiency for light oils lies in the order LGO > CLO > LCO. This is the same as that of the aromatic concentration in light oils, and demonstrates that high-aromaticcontent light oil is difficult to desulfurize. The sulfones formed by oxidization are not only removed into the aqueous phase but also form an insoluble precipitate and remain in the light oil. The low desulfurization efficiency for light oils is caused by the accumulation of sulfones in the resulting oil.

The second step of this process is the removal of the oxidized compounds by contacting the distillate with a selective extraction solvent. The liquid-liquid extraction technique using water-soluble polar solvents e.g. dimethylsulfoxide (DMSO), dimethylformamide (DMF) and acetonitrile is usually employed. The former two solvents have a high extractability for sulfones but have a high boiling point at $300{ }^{\circ} \mathrm{C}$, which is close to the boiling point of the sulfones, and thus they may not be reused for further extraction based on recovery by distillation. On the contrary, acetonitrile was used as the extraction solvent, since it has a relatively low boiling point $\left(82{ }^{\circ} \mathrm{C}\right)$ and is separated easily from the sulfones by distillation. When acetonitrile is contacted with light oil, a large quantity of aromatics is extracted simultaneously with the sulfones. The addition of water however suppresses the extractability of the sulfones. Therefore the solvents should be sufficiently polar to be selective for polar compounds in the process of extraction. Examples of polar solvents include those with high values of the Hildebrand solubility parameter " $\Delta$ "; liquids with a $\Delta$ higher than about 22 have been successfully used to extract these compounds. However, as it will be obvious to those skilled in the arts, mere polarity considerations are insufficient to define successful extraction solvents. Methanol, for instance, has sufficient polarity, but its density, $0.79 \mathrm{~g} \mathrm{~cm}^{-3}$, is about the same as that of typical light oil, making separations very difficult. Other properties to be considered include boiling point, freezing point, and surface tension. Surprisingly, the combination of the properties exhibited by DMSO makes it an excellent solvent for extracting oxidized sulfur and nitrogen compounds from liquid light oil. 


\subsection{Developments}

This two-stage process was put forward in 1974 by using nitrogen dioxide $\left(\mathrm{NO}_{2}\right)$ as an oxidant followed by extraction with methanol to remove both $\mathrm{S}$ - and $\mathrm{N}$-containing compounds from petroleum feedstocks. ${ }^{5-7}$ Then in 1988, a process was described for purifying hydrocarbon aqueous oils containing both heteroatom sulfur and heteroatom nitrogen compound impurities, such as shale oils, by first reacting the oil with an oxidizing gas containing $\mathrm{NO}_{2}$ and then extracting the oxidized oil with solvents in two stages (amines and formic acid). ${ }^{8}$ The oxidized products are composed of a liquid phase and a byproduct that is a semisolid-like residue with high S-content. However, the interest has been quickly increased at the beginning of 2000s, in parallel with more restrictive limitations of sulfur concentration in fuels, and the need to eliminate less reactive sulfur compounds in HDS.

\subsubsection{Organic peracids}

The peracids are very powerful oxidizing agents, and are able to oxidize sulfur compounds. These compounds are highly reactive and corrosive, and for this reason are produced in situ by reaction of hydrogen peroxide and a carboxylic acid, in general formic acid or acetic acid. First studies have been based in the direct use of peracids in the oxidation of sulfur compounds. ${ }^{9-13}$ However, the amount of oxidizing agent employed is very high in comparison to the sulfur removed; in consequence this procedure is difficult to be feasible economically. For this reason, the addition of catalysts that can oxidize the sulfur compound more efficiently was necessary. The most common option is the use of transition metal salts, and specifically tungsten salts ${ }^{14,15}$ which are very active and selective in the oxidation of sulfur compounds with peracids. Modified active carbons are also catalysts for this reaction. ${ }^{16-18}$ In the presence of active carbon with carboxylic groups more sulfur is removed (>95\%) from the fuel than in their absence (60\%). ${ }^{16} \mathrm{~A}$ second option is to use transition metal salts like Co ${ }^{19,20}$ or Fe ${ }^{21}$, that are able to form radicals from peracids ( $\mathrm{R}$ COOO.); these radicals are very reactive and have high oxidation capacity. A similar approach has been used by the addition of other substances such as $\mathrm{SiO}_{2}{ }^{22}$ or $\mathrm{NaHCO}_{3}{ }^{23}$

Peracids and their solvents (short-chain carboxylic acids) used in these reactions are highly polar and form two immiscible liquids phases in the reactor. For this reason there is some mass transfer limitation between the fuel and the polar phase containing the oxidizing agent. Accordingly, some studies of the use of phase transfer compounds have been carried out. The presence of the phase transfer compound facilitates the transfer of products and 
reagents at the polar-apolar interface, increasing notably the mass transfer across the interphase. $^{24,25}$

Finally, some authors have proposed the oxidation of sulfur compounds with oxygen and sacrificial aldehydes. These aldehydes are very weakly oxidized with oxygen to form peroxo-compounds or peracids in the presence of a transition metal salt $(\mathrm{Co}, \mathrm{Ni})$, and this oxidizing agent is able to oxidize sulfur compounds. ${ }^{26,27}$

\subsubsection{Organic Hydroperoxides}

A second family of oxidants that has been studied is based on the use of organic hydroperoxides. The most important advantage of this system is simple reactor engineering, enabling the application of a fixed bed system. The most widely hydroperoxide employed is t-butylhydroperoxide (TBHP). An ODS process based on this oxidant was patented by Lyondell Chemicals $^{28-30}$ and EniChem/UOP. ${ }^{31,32}$ The Lyondell process uses extraction for separation of sulfone, while EniChem/UOP removes sulfone species by adsorption. A major drawback is the high cost of t-butylhydroperoxide, and the waste treatment of the t-butyl alcohol by-product generated, as well as sulfone waste treatment. They suggest the use of tbutyl alcohol as a potential octane-boosting compound for gasoline. Another important drawback is the low amount of active oxygen by mass unit (17-10\%). For this reason the transportation of this compound is very expensive, and in consequence is recommended to install a hydrocarbon oxidation unit to produce hydroperoxides, with an increase in capital costs.

The oxidation of sulfur compounds with organic hydroperoxides occurs in the presence of catalysts. The active center of these catalysts is a transition metal in a high oxidation state with Lewis acidity, such as: Mo(IV), Ti(IV), V(V), W(IV), etc.. Most of the studies have been focused on molybdenum catalysts, $^{33-39}$ and they usually employ heterogeneous $\mathrm{Mo} / \mathrm{Al}_{2} \mathrm{O}_{3}$ catalysts. However, molybdenum tends to be leached into the reaction medium, where the catalysts are not very stable and the main part of the catalytic activity is due to the solubilized molybdenum. ${ }^{40}$ Thus more stable catalysts for example $\mathrm{Co} / \mathrm{Mn}^{35}$, Ti-silica ${ }^{29,} 30$ or Ti-MCM- $41^{30,41}$ have been proposed. These catalysts are really heterogeneous. The best results have been obtained with titanium catalysts and their silylation improves their activity and longevity. ${ }^{41}$

Although the most commonly used hydroperoxide is t-butylhydroperoxide, other oil- 
soluble alkyl peroxides have also been tried. Their reactivity in the oxidation of sulfur compounds is as follows: cyclohexanone peroxide > tert-amyl hydroperoxide > tert-butyl hydroperoxide. ${ }^{42}$ Cyclohexanone peroxide is formed by reaction with hydrogen peroxide, ${ }^{36}$ and makes it less competitive than other hydroperoxides which are produced by hydrocarbon autoxidation.

\subsubsection{Hydrogen Peroxide}

The best candidate as an oxidizing agent is hydrogen peroxide. This presents a high amount of active oxygen by mass unit (47\%). It is a commercial product often used at industrial level, and gives only water as a by-product. ${ }^{43} \mathrm{~A}$ catalyst is required so that the hydrogen peroxide efficiently oxidizes the sulfur compounds.

The first papers of the ODS with hydrogen peroxide are related to the use of a photosensitizer. ${ }^{44-47}$ This compound is excited under light radiation and then activates the sulfur compound, and these excited compounds are then oxidized by the hydrogen peroxide. Especially effective is benzophenone. ${ }^{45}$ Under these conditions, the desulfurization of commercial light oil was also achieved and the sulfur content was reduced from 0.2 to 0.05 $\mathrm{wt} \%$ by $48 \mathrm{~h}$ photo-irradiation. But this long reaction time makes this process not applicable at an industrial level.

The second group of catalysts is based on transition metal salts in a high oxidation state with Lewis acidity. ${ }^{40,48-57}$ Working under these reaction conditions, the reaction time can be reduced to less than $2 \mathrm{~h}$. However, these reaction times are still too high to be integrated in a refinery. The main problem is related to the presence of two reaction phases: an oil phase with the sulfur compound and a polar phase that contains the oxidant $\left(\mathrm{H}_{2} \mathrm{O}_{2}\right)$, which is not soluble in the oil phase. For this reason, some authors have studied the use of phase transfer catalysts. ${ }^{58-66}$ The presence of the phase transfer agent facilitates the transfer of products and reagents at the polar-apolar interface, notably increasing mass transfer across the interphase. Such a biphasic oxidation reaction follows the cycle illustrated in Scheme 4. In the polar phase, the catalyst precursor is rapidly oxidized by $\mathrm{H}_{2} \mathrm{O}_{2}$. The resulting peroxo-compound is transferred to the apolar phase by $\mathrm{H}^{+}-\mathrm{Q}^{+}$ion exchange with the phase transfer agent $\left(\mathrm{Q}^{+}\right)$. The peroxo-compound in the apolar phase oxidizes thioethers into sulfones, which can then be regenerated at the liquid-liquid interface with $\mathrm{H}_{2} \mathrm{O}_{2}$ or transferred to the polar phase where it reacts with hydrogen peroxide. Then, the sulfones obtained are transferred to the polar phase due the solubility of sulfones in a polar solution, 
giving the production of a sulfur free polar phase. But still, mass transfer limitations makes this reaction too slow for industrial use so some very interesting approaches have been studied, including the use of microemulsions ${ }^{67,68}$ and microstructured reactors. ${ }^{69}$ In both cases the distances between bulk and interphase are significantly reduced. In consequence mass transfer limitations are avoided.

The ideal systems use heterogeneous catalysts. Consequently, efforts have been devoted to the development of processes using highly robust and recyclable catalysts which provide higher atom utilization and minimize pollution levels using greener ingredients. Over the last few years selective oxidation of sulfur-containing compounds by $\mathrm{H}_{2} \mathrm{O}_{2}$ has been carried out using a large number of solid redox catalysts: $\mathrm{Ti}^{70-81}, \mathrm{~V}^{82-87}, \mathrm{~W}^{88-94}, \mathrm{Mo}^{95,}{ }^{96}$, $\mathrm{Co} / \mathrm{Mn}^{97}, \mathrm{Ag}^{98}, \mathrm{Au}^{99}, \mathrm{Re}^{100}$.

\subsubsection{Ionic Liquids extraction and ODS}

Over the past years the desulfurization of various motor fuels has been suggested to be performed by extraction with ionic liquids (ILs). ${ }^{42,101}$ lonic liquids containing $\mathrm{Cu}(\mathrm{I})$ and $\mathrm{Ag}(\mathrm{I})$ ions were found to be especially efficient due to their tendency to form $\pi$ complexes with thiophene derivatives. An interesting example is the application of ILs obtained by reaction of 1-butyl-3-methylimidazolium chloride (BMImCl) with anhydrous powdered $\mathrm{CuCl}$, containing $\mathrm{CuCl}_{2}^{-}, \mathrm{Cu}_{2} \mathrm{Cl}_{3}^{-}$, and $\mathrm{Cu}_{3} \mathrm{Cl}_{4}^{-}$anions that are resistant to moisture and air, for desulfurization of a model fuel. ${ }^{102}$ These systems revealed a high desulfurizing activity toward gasoline; for instance, the ionic liquid $\mathrm{BMImCu}_{2} \mathrm{Cl}_{3}$ extracted $23 \%$ of sulfur compounds, whereas $\mathrm{BMImBF}_{4}$ extracted no more than $11 \%$. Potent complex-forming agents dissolved in gasoline hinder extraction of sulfur compounds with IL.

Studies of the ability of 1,3-dimethylimidazolium dimethylphosphate [MMIM][DMP] and 1-butyl-3-methylimidazolium dibutylphosphate [BMIM][DBP] to extract sulfur from diesel fuel over a wide range of sulfur concentrations, showed that the solubility of dibenzothiophene and benzothiophene in aqueous solutions of ILs at $25^{\circ} \mathrm{C}$, varies in the following order: $[\mathrm{BMIM}][\mathrm{DBP}]>[\mathrm{EMIM}][\mathrm{DEP}]>[\mathrm{MMIM}][\mathrm{DMP}]$. Therefore, dibenzothiophene is more soluble than benzothiophene. ${ }^{103}$ Of the ILs studied, the most suitable for desulfurization of diesel fuel was found to be [EMIM][DEP] which is fairly highly reactive toward sulfur, poorly soluble in fuel, and only slightly affects other properties of the fuel. Of interest is the use in desulfurization of gasolines of ILs synthesized from organic acids (formic, acetic, and benzoic) and nitrogenous bases (aniline, piperidine, and diethylamine).$^{42}$ 
After three separate extractions of catalytic cracking gasoline with the ILs mentioned above, the sulfur content of the latter decreased from 240 to $30 \mathrm{ppm}$, and the content of aromatic hydrocarbons, from 26 to $14 \%$. Ionic liquids can be regenerated by treatment of the extract with an excess of low-boiling paraffins and repeatedly used for desulfurization. The high efficiency of ILS in desulfurization of diesel fuel was demonstrated by the example of ILS containing 1-butyl-3-methylimidazolium as cation and tetrafluoroborate, hexafluorophosphate, octyl sulfate, ethyl sulfate, and dimethyl phosphate. ${ }^{104}$ The suggested technological scheme involving the steps of extraction and regeneration of ILs allows reduction of the sulfur content of diesel fuel from 500 to $10 \mathrm{ppm}$.

As a general rule, ILs themselves, in the absence of oxidants, fail to provide a high degree of sulfur removal. ${ }^{105-110}$ For example, the ionic liquid [ $\left.\mathrm{HMIm}\right] \mathrm{BF}_{4}$ is able to remove only $6 \%$ of the sulfur, but in the presence of hydrogen peroxide gave a sulfur removal of 65 , 70 , and $93 \%$ at 70,80 , and $90{ }^{\circ} \mathrm{C}$, respectively ${ }^{105}$ and has proved to be a promising desulfurization method. This effect can be related to the similar polarity between alkenes, aromatics, and the sulfur compounds, and the sulfur removal is improved increasing the polarity of sulfur oxidizing sulfur compounds to the corresponding sulfoxides and sulfones. However, when only ionic liquids are employed a very high $\mathrm{H}_{2} \mathrm{O}_{2} / \mathrm{S}$ ratio is necessary to reach these sulfur removal levels. This drawback can be avoided by use of catalysts: Brønsted organic acids, ${ }^{111-114}$ photocatalysts, ${ }^{115}$ tungsten and molybdenum peroxo complexes, ${ }^{106,} 110$ sodium molybdate, ${ }^{116}$ vanadium oxide, ${ }^{117}$ iron catalyst $^{118,119}$ or phosphotungstic acid ${ }^{120-122}$ can remove the majority of sulfur with a low hydrogen peroxide sulfur ratio. This finding provides evidence in favour of combining catalytic oxidation and extraction.

\subsection{Challenges for ODS}

ODS has proved that it is possible to remove sulfur compounds from fuels to meet strict regulation limits. Among different chemical oxidants the best option is hydrogen peroxide. Using this oxidant the oxidation/extraction is simultaneous and can reach very high levels of sulfur removal. However, in order to make an ODS process competitive with deep HDS a three-step process is needed: (i), improvement of the catalytic specific activity at low $\mathrm{H}_{2} \mathrm{O}_{2} / \mathrm{S}$ ratios; (ii), increase of the mass transfer in a biphasic system containing an oil fraction and polar phase; and (iii), enhancement of the post-treatment of sulfones produced.

2.3.1 Improvement of catalytic activity at low $\mathrm{H}_{2} \mathrm{O}_{2} / \mathrm{S}$ ratios 
A lot of catalytic systems are very active in the oxidation of sulfur compounds. However, only some catalysts are able to oxidize in a short reaction time $(<15 \mathrm{~min}$ ) operating with a hydrogen peroxide/sulfur molar ratio close to the stoichiometric $\left(\mathrm{H}_{2} \mathrm{O}_{2} / \mathrm{S}=\right.$ 2). To get a commercially competitive process it is necessary to work with as small as possible amount of oxidant. Liquid fuels are very complex mixtures that contain alkenes and aromatics, and these compounds can also be oxidized consuming part of the oxidant and degrading the quality of the fuel. These undesirable oxidation reactions are evident at temperatures of about $80-90{ }^{\circ} \mathrm{C}$, for this short reaction time $(<15 \mathrm{~min}) .{ }^{123}$ For this reason, the reaction has to be conducted at temperatures lower than $80{ }^{\circ} \mathrm{C}$ and short reaction times for real fuels.

Another important matter for improvement is the relative reactivity against different sulfur compounds. While the relative oxidation reactivity of small peracids (formic or acetic) is 4,6-DMDBT > 4-MDBT > DBT ${ }^{9,} 49$ this is the opposite to HDS and thus makes a very good complement to HDS. When a catalyst is employed, which may be homogeneous or heterogeneous, the relative oxidation reactivity is different: DBT > 4-MDBT > 4,6-DMDBT > BT. ${ }^{49,60}$ The relative reactivity of DBT and substituted DBT compounds appear to be related to the steric hindrance of the ethyl and methyl groups at positions 4 and 6 in the DBT molecule, which hinders the formation of reaction intermediates prior to being oxidized, while it is more difficult to oxidize in terms of S-C bond stabilization in the BT molecule. ${ }^{9,49,60}$ In consequence, the activity in oxidation of substituted DBT compounds must be improved, because these compounds are present in treated diesel stream, and make it difficult to reach the very restrictive environmental regulations.

\subsubsection{Increase the mass transfer in the reactor}

The reaction is conducted in the presence of two liquid reaction phases: an oil phase with the sulfur compound and a polar phase that contains the oxidant agent $\left(\mathrm{H}_{2} \mathrm{O}_{2}\right)$, which is not soluble in the oil phase. In consequence, the overall sulfur removal rate is limited by the mass transfer between phases with very active catalysts. For this reason, an increase in the mass transfer clearly improves the overall sulfur removal rate. Some attempts have been made employing microemulsions ${ }^{67,68}$ and microstructured reactors. ${ }^{69}$ Microemulsions are interesting from the conceptual point of view, but need intense development to be able to be applied in a refinery process. A very interesting concept is the use of microstructured reactors. Chemical microstructured reactors (MSR) are devices containing open paths for 
fluid flow with dimensions in the sub-millimeter range. Most of MSRs are designed as multiple parallel channels with diameters between ten and several hundred micrometers where the chemical transformation occurs. ${ }^{124}$ This gives a high specific surface area in the range of 10,000 to $50,000 \mathrm{~m}^{2} / \mathrm{m}^{3} 124,125$ and allows an effective mass and heat transfer if compared to more traditional chemical reactors having $\approx 100 \mathrm{~m}^{2} / \mathrm{m}^{3}$. These reactor systems can improve the mass transfer 100 times. Another interesting alternative is the use of ultrasound-assisted oxidative desulfurization (UAOD). This process could play an important role in future technology to produce low and/or ultra-low sulfur fuels, offering a nonhydrogen consuming process with a lower cost when compared to conventional HDS technology. Although this technology can be considered as an attractive strategy to desulfurize fuels, few studies related to the application of ultrasound in the petroleum field have been reported. $23,25,59,63,126$

Process-engineering research must decrease the volumetric reaction rate (polar solvent/oil ratio). The solvent/oil volume ratio is among the most important technical bottlenecks in the development of ODS processes, and in order to reduce operational costs associated with handling, separation and disposal of water, ideally the volume ratios of solvent/oil should be minimized.

\subsubsection{Enhancement the post treatment of the sulfones produced}

The concentration of sulfur compounds are very low but the refinery stream to be treated is huge, in consequence the amount of sulfones produced is large. Some sulfones can be used as chemical intermediates but in a real fuel the variety of sulfur compounds is very high, and thus the number of different sulfones is also high and very difficult to separate. For these reasons, adequate post-treatment of the sulfones produced is very important. The amount of fuel lost in ODS process depends on the initial sulfur concentration and the amount of sulfur removed. For instance $1,000 \mathrm{ppm}$ of $\mathrm{S}$ removed implies a decrease of about 5-6 \% of fuel mass. For this reason, it is very interesting to recover, at least in part, the hydrocarbon portion of the oxidized sulfur compounds.

The first option is to treat these sulfones to eliminate the sulfur and produce a S-free fuel. The oxidized sulfur-containing hydrocarbon is contacted with a metal to form a metalsulfur containing compound. This process therefore relies on the adsorption of oxidized sulfur compounds from the hydrocarbon using a metal capable of forming a metal sulfide. The metal is selected from the group consisting of $\mathrm{Ni}, \mathrm{Mo}, \mathrm{Co}, \mathrm{W}, \mathrm{Fe}, \mathrm{Zn}, \mathrm{V}, \mathrm{Cu}, \mathrm{Mn}, \mathrm{Hg}$, and 
mixtures thereof. This process is distinguished from conventional hydrodesulfurization in that the sulfur is immobilized in the form of a metallic sulfur compound (e.g. a metal sulfide) rather than being converted to hydrogen sulfide. For this reason, the addition of free molecular hydrogen, as is required in hydrodesulfurization, is overcome. The second option is the catalytic decomposition on acid/basic solid catalysts, like zeolites or silica-alumina; ${ }^{31,32}$ or basic catalysts like MgO or hydrotalcite. ${ }^{31,32}$ This catalytic conversion takes place under relatively mild conditions, without the use of a hydrogen atmosphere. However, these processes need to be improved.

\section{Biodesulfurization (BDS)}

One of the alternative options to remove sulfur from fossil fuel is by biological methods. Sulfur atoms form $0.5-1 \%$ of bacterial cell dry weight. Microorganisms require sulfur for their growth and biological activities. Sulfur generally occurs in the structure of some enzyme cofactors (such as coenzyme $A$, thiamine and biotin), amino acids and proteins (cysteine, methionine, and disulfur bonds). ${ }^{127,128}$ Energy BioSystems Corporation (EBC) was the only commercial venture dedicated to the development of biodesulfurization technology. EBC's concept for a biodesulfurization process was to treat diesel, but also to produce a value-added surfactant by-product to achieve a more economical process. ${ }^{129,130}$ Some reviews have been recently published in this field, ${ }^{131,132}$ and for this reason we will focus on a general description of the process and on some improvements necessary to develop a BDS process.

Microorganisms, depending on their enzymes and metabolic pathways, may have the ability to provide their required sulfur from different sources. Some microorganisms can consume the sulfur in thiophenic compounds such as DBT and reduce the sulfur content in fuel. In terms of DBT utilization, two main pathways have been reported: ring-destructive (degradation) and sulfur-specific (desulfurization) pathways. To date, two ring-destructive pathways for metabolism of DBT have been recognized.

\subsection{Destructive biodesulfurization}

The most common pathway of DBT degradation, known as the 'Kodama pathway' (Scheme 5), is analogous to that of naphthalene degradation. ${ }^{133}$ In this pathway initial dioxygenation is carried out at the peripheral aromatic ring of DBT, followed by cleavage of 
the ring (Fig. 1). This process leads to the accumulation of 3-hydroxy-2formylbenzothiophene as a water-soluble end product, with lower carbon content than DBT. In this pathway no desulfurization of the organosulfur substrate occurs. Denome et al. cloned and sequenced a $9.8 \mathrm{~kb}$ DNA fragment from Pseudomonas strain C18 that encoded DBT-degrading enzymes. ${ }^{134}$ Nine ORFs were identified and designated doxABDEFGHIJ; collectively, these genes were referred to as the DOX (DBT oxidation) pathway. The results indicated that a single genetic pathway controls the metabolism of DBT, naphthalene and phenanthrene in strain C18.

Another ring-destructive pathway that results in mineralization of DBT is that described by van Afferden et al. ${ }^{135}$ They isolated Brevibacterium sp. DO, capable of using DBT for growth as the sole source of carbon, sulfur and energy. During DBT mineralization three metabolites were identified: DBT sulfoxide (DBTO), DBT sulfone $\left(\mathrm{DBTO}_{2}\right)$ and benzoate. This pathway resulted in the complete mineralization of DBT, with the stoichiometric release of the sulfur atom as sulfite, which then oxidized to sulfate. There are no detailed studies of the enzymology or molecular biology of DBT degradation by this strain. This ring-destructive pathway may be valuable in biodegradation of DBT in the environment.

The above ring-destructive pathways are not commercially useful for the petroleum industry, because use of the carbon skeleton of sulfur compounds by the bacteria reduces the fuel's calorific value.

\subsection{Specific oxidative biodesulfurization}

Kilbane ${ }^{136}$ proposed a hypothetical oxidative desulfurization pathway that, if it ever existed in nature, could specifically remove sulfur from DBT. The pathway was named as $4 \mathrm{~S}$ and implied consecutive oxidation of DBT sulfur to sulfoxide (DBTO), sulfone $\left(\mathrm{DBTO}_{2}\right)$, sulfinate (HPBS) and hydroxybiphenyl (HBP) as shown Scheme 6.

Several researchers tried to isolate microorganisms that could remove sulfur nondestructively. Afferden et al. ${ }^{137}$ isolated Brevibacterium sp. DO, which during the growth associated condition, could consume DBT as the sole sulfur and carbon sources. The pathway of DBT degradation by this strain was different from Kodama, and partly similar to $4 S$ pathways. This bacterial strain could transform DBT to DBTO and then to DBTO 2 . Sulfur in $\mathrm{DBTO}_{2}$ was removed to form $\mathrm{SO}_{3}{ }^{2-}$ and $\mathrm{SO}_{4}{ }^{2-}$ consecutively. With the removal of sulfur, $\mathrm{DBTO}_{2}$ was converted to benzoate and then was mineralized to water and carbon dioxide. ${ }^{137}$ 
Although the desulfurization pathway was reported to be partly similar to the 45 pathway, it was still carbon-destructive because the aromatic compounds were degraded during the desulfurization process.

From the first studies, tremendous efforts have been made to increase knowledge of the desulfurization enzymes, reactants and intermediate substrates, the machinery of the pathway, in order to obtain a better BDS process (see and references therein). The dszC gene encodes dibenzothiophene monooxygenase (DszC) that catalyzes the conversion of DBT into DBT sulfone (DBTO2). The dszA gene encodes dibenzothiophene-5,5-dioxide monooxygenase (DszA) that catalyzes the conversion of DBTO2 into 2-hydroxybiphenyl-2sulfinate (HBPSi). The dszB gene encodes 2-hydroxybiphenyl-2-sulfinate sulfinolyase (DszB) that catalyzes the conversion of HBPSi into 2-hydroxybiphenyl (2-HBP) and sulfite. The dszABC genes are transcribed as an operon found on a large plasmid, pSOX, in many desulfurization-competent bacteria. ${ }^{138}$ An unlinked fourth gene, the dszD gene encoding an NADH-FMN oxidoreductase (DszD), is an accessory component of the desulfurization pathway and allows the regeneration of the cofactors needed for the monooxygenase reactions catalyzed by DszC and DszA. The enzymology of the oxidative desulfurization pathway has been firmly established using purified enzymes from several desulfurization competent bacterial species and from the results of genetic analyses. ${ }^{139,} 140$

\subsection{Thermophilic biodesulfurization}

It is presumed that most sulfur compounds will be desulfurized by the HDS process in petroleum refining, after which the BDS process will be applied to desulfurize the more recalcitrant sulfur compounds. In a petroleum refinery process, fractional distillation and desulfurization reactions are carried out at high temperatures. To incorporate a BDS step into the petroleum refining process it is desirable that the BDS reaction is also carried out at a high temperature. Better understanding of thermophilic biodesulfurization will help to optimize the integration of BDS process into refineries.

Most of the DBT-desulfurizing micro-organisms so far reported are mesophiles. For high-temperature desulfurization it is preferable to use a microorganism capable of both growing and desulfurizing organic sulfur compounds at high temperatures. Several research groups have been working to isolate and characterize thermophilic desulfurizing bacteria. ${ }^{131}$ Elevated temperatures provide several advantages: higher temperature decreases oil 
viscosity, makes molecular displacement easier, improves enzymic rates, and decreases bacterial contamination. ${ }^{132,139}$

Improved thermostability of the desulfurization enzymes is also needed. The more rapid thermal inactivation of purified desulfurization enzymes as compared with desulfurization activity detected in whole cells requires further investigation. Through the use of mutagenesis combined with natural selection, directed evolution can be employed to obtain thermostable derivatives of the desulfurization enzymes.

\subsection{Challenges for BDS}

In order to make a BDS process competitive with deep HDS a five-step process is needed: (i), production of active resting cells (biocatalysts) with a high specific activity; (ii), preparation of a biphasic system containing oil fraction, aqueous phase and biocatalyst; (iii), biodesulfurization of a wide range of organic sulfur compounds at a suitable rate; (iv), separation of desulfurized oil fraction, recovery of the biocatalyst and its return to the bioreactor; and (v), efficient wastewater treatment. Each step is affected by a number of factors. In this section the limitations and solutions will be discussed.

\subsubsection{Biocatalyst activity improvement}

The desulfurization rate obtained with crude oil or a petroleum product is an important measurement in determining the suitability of a biocatalyst for an industrial BDS process. The currently available biocatalysts require an increase in desulfurization rate of about 500 fold. ${ }^{130}$ Since 1990 researchers at EBC have increased the biocatalyst activity level more than 200 fold in experiments using model oil $(0.6 \%, w / w$, DBT dissolved in pure hexadecane). Improvements in biocatalyst activity have been achieved in several steps, including optimization of biocatalyst production conditions, increasing Dsz enzyme concentrations through genetic engineering, recognition of need for high levels of DszD enzyme, optimization of the catalyst design with all four enzymes, removal of the DszB enzyme, and optimization of media used in the bioreactor itself. ${ }^{131}$

\subsubsection{Biocatalyst longevity improvement}

Another barrier to commercial acceptance of BDS involves the logistics of sanitary handling, shipment, storage and use of living bacterial cells within the refinery environment. The biocatalyst can regenerate enzymes destroyed or lost during the reaction process; it can 
reproduce itself. The EBC's original BDS process had unacceptable catalyst longevity of only 1-2 days. The next design included the production and regeneration of the biocatalyst within the BDS process, with biocatalyst longevity in the range of 200-400 h. ${ }^{141}$ Some improvements have been obtained by immobilization of cells, R. erythropolis KA2-5-1 were immobilized by entrapping them with the photocrosslinkable resin prepolymer ENT-4000. ENT-4000-immobilized cells could catalyze BDS of model oil (DBT-containing n-tetradecane) repeatedly in this system for more than $900 \mathrm{~h}$ with reactivation. ${ }^{142}$

\subsubsection{Phase contact and separation}

A very important problem with BDS is the presence of organic solvents that are not compatible with most bacterial species. In consequence, the development of microorganisms that are stable and active in the presence of non-aqueous solvents is desirable in the biocatalytic upgrading of crude oil fractions. In the BDS bioreactor, a limiting factor is the transport rate of the sulfur compounds from the oil phase to the bacterial cell membrane. To facilitate this mass transfer the addition of surfactants has been tested and the BDS activity was enhanced. ${ }^{143}$ One problem, which has yet to be resolved, is whether the chemical surfactants would be toxic to the process organisms or act against the characteristic adhesion mechanisms of the bacteria to oil droplet surfaces. ${ }^{144}$

In some bioreactors, such as mechanically mixed reactors and electro-spray reactors, emulsions are created. In these conditions emulsion stabilization can help prolong the longevity of the emulsion created. The resting cells may stabilize oil-water emulsions. ${ }^{145}$ Under these conditions the maximum surface exposure is provided and therefore the mass transfer from oil droplets to the resting cells is more rapid. As stabilized emulsions are formed, there may be a difficulty associated with separation. Several solutions to this problem have been suggested, including: (i), avoiding the formation of a stable water-in-oil emulsion, in order to facilitate oil recovery; (ii), the use of emulsion-destabilizing chemical agents; and (iii), a cell-immobilized BDS process. ${ }^{142,146,147}$

\subsubsection{Process engineering research}

There are very few reports on BDS process designs and cost analysis. In order to ensure that capital and operating costs for BDS will be lower than for HDS it is necessary to design a suitable biocatalytic process. ${ }^{129}$ The cost of building a bioreactor can be reduced by changing from a mechanically stirred reactor to air-lift designs. An air-lift reactor was used at 
EBC to minimize energy costs. ${ }^{129,131}$ However, specific details about the EBC process and the results achieved were not published. ${ }^{131}$ Lee et al. investigated diesel oil desulfurization in a combination of air-lift/stirred-tank reactor using immobilized cells of Gordonia nitida CYKS1. ${ }^{132,147}$

Process-engineering research can decrease the volumetric reaction rate (water/oil ratio). The water/oil volume ratio is among the most important technical bottlenecks in the development of petroleum biotechnological processes, and in order to reduce operational costs associated with handling, separation and disposal of water, ideally the volume ratios of water/oil should be minimized. The use of immobilized biocatalysts was considered to be a potential alternative. ${ }^{142,146}$

\section{CONCLUDING REMARKS}

Desulfurization at moderate conditions (ODS or BDS) is estimated to have $70-80 \%$ lower $\mathrm{CO}_{2}$ emissions. In order to reach adequate efficiency levels, the capital cost required for an industrial oxidative/biodesulfurization process is predicted to be two thirds of that for an HDS process. Oxidative/ biodesulfurization operating cost is also expected to be $15 \%$ lower. ${ }^{148}$ The operating cost of an oxidative/biodesulfurization unit is estimated to be 10$15 \%$ lower than a HDS unit. ${ }^{132,149,150}$

ODS has made a lot of progress recently and has proved that it is possible to remove sulfur compounds from fuels to meet strict regulation limits. Among different chemical oxidants the best option is hydrogen peroxide. Using this oxidant the oxidation/extraction is simultaneous and can reach very high levels of sulfur removal. This option is close to development for use at industrial levels, and is an option to replacement of deep desulfurization processes. However, we do not consider that at present ODS is an alternative to HDS. Because hydrotreatment improves the quality of the fuels that cannot be produced in ODS, we think that ODS is a complementary option, and it is able to remove refractory sulfur compounds that force HDS units to work at high temperature, high hydrogen pressure and low space velocity to reach the present sulfur levels on fuels regulations.

One of the drawbacks of the development of ODS, is the need to feed hydrogen peroxide which is not present in a refinery, and its price is relatively high. For this reason, some approaches take into account possible integration of a hydrogen peroxide synthesis in the process. 
Some improvements in the reaction system have to be included. Especially interesting are those related to the improvement of the mass transfer between oil and polar phase. Among several options, microstructured reactors are a very interesting option. In this case, it is highly recommended that the catalyst design should be closely integrated with the reactor design taking into consideration the reaction mechanism, catalytic activity, catalyst life time (and exchangeability).

Finally, the next challenge for chemical ODS is to obtain a catalyst able to oxidize selectively sulfur compounds in fuels with oxygen, and in this case avoid the use of liquid oxidants like hydrogen peroxide.

In order to develop BDS as a complementary process the interdisciplinary participation of experts in biotechnology, biochemistry, refining processes and engineering will be essential. Over the last two decades several research groups have attempted to isolate and characterize bacteria capable of desulfurizing oil fractions. Further research into BDS development is required before realistic assessments in pilot-plant studies can be made. It will be difficult to be competitive with chemical desulfurization, which has also made a lot of progress recently.

For any process to be viable in the petroleum industry it must not only be capable of treating the complex mixture of chemicals that constitute petroleum but it must also treat very large volumes cost-effectively. The two main steps to the commercial success of BDS are: (i), to continue making rapid technical progress; and (ii), to find optimum ways to integrate biotechnology into the refineries.

Biodesulfurization from a process point of view at least, consists of feedstock preparation, microorganism/biocatalyst preparation, desulfurization in a bioreactor, and separation and recovery. Among all the stated items, preparation of biocatalysts with a long half-life, high and reproducible specific activity is important. To date, the most important challenge to confront industry level biodesulfurization is the search to isolate a strain with higher biodesulfurization activity or to design a recombinant biocatalyst with a stable activity to work in tandem with refining pace. Apart from this, more work is required to obtain higher desulfurization specific activity by increasing the driving force from one phase to another and preventing the accumulation of inhibitors. One of the points that might accelerate biodesulfurization is to eliminate the cooling time required after HDS. 
In addition, the BDS process must operate at the same speed and reliability as other refinery processes so as not to disrupt normal refining operations. Thus despite the great interest and potential of BDS, it will be challenging to develop it to a stage where it can be practically implemented in refineries.

\section{ACKNOWLEDGEMENTS}

We are grateful to many of our colleagues for stimulating discussions and to our research sponsor Ministerio de Educación y Ciencia (Spain) under grant ENE2007-07345-C0301/ALT.

\section{REFERENCES}

1. Song $\mathrm{C}$ and $\mathrm{Ma} \mathrm{XL}, \mathrm{New}$ design approaches to ultra-clean diesel fuels by deep desulfurization and deep dearomatization. Appl Catal B-Environ 41:207-238 (2003).

2. Song CS, An overview of new approaches to deep desulfurization for ultra-clean gasoline, diesel fuel and jet fuel. Catal Today 86:211-263 (2003).

3. Song CS and Ma XL, Ultra-deep desulfurization of liquid hydrocarbon fuels: Chemistry and process. Int J Green Energy 1:167-191 (2004).

4. Babich $\mathrm{VI}$ and Moulijn JA, Science and technology of novel processes for deep desulfurization of oil refinery streams: A review. Fuel 82 (2003).

5. Guth E and Diaz A, Method for removing sulfur and nitrogen in petroleoum oils. US Patent 3847800 (1974).

6. Tam PS, Kittrell JR and Eldridge JW, Desulfurization of fuel oil by oxidation and extraction. 1. Enhancement of extraction oil yield. Ind Eng Chem Res 29:321-324 (2002).

7. Tam PS, Kittrell JR and Eldridge JW, Desulfurization of fuel oil by oxidation and extraction. 2. Kinetic modeling of oxidation reaction. Ind Eng Chem Res 29:324-329 (2002).

8. Darian ST and Arabshshi SH, Process for upgrading diesel oils. US Patent 4746420 (1988).

9. Otsuki S, Nonaka T, Takashima N, Qian WH, Ishihara A, Imai T and Kabe T, Oxidative desulfurization of light gas oil and vacuum gas oil by oxidation and solvent extraction. Energy Fuels 14:1232-1239 (2000).

10. De Filippis $P$ and Scarsella $M$, Oxidative desulfurization: Oxidation reactivity of sulfur compounds in different organic matrixes. Energy Fuels 17:1452-1455 (2003).

11. Dehkordi AM, Sobati MA and Nazem MA, Oxidative desulfurization of nonhydrotreated kerosene using hydrogen peroxide and acetic acid. Chin J Chem Eng 17:869-874 (2009).

12. Yazu K, Makino $M$ and Ukegawa K, Oxidative desulfurization of diesel oil with hydrogen peroxide in the presence of acid catalyst in diesel oil/acetic acid biphasic 
system. Chem Lett 33:1306-1307 (2004).

13. Ali SH, Hamad DM, Albusairi BH and Fahim MA, Removal of dibenzothiophenes from fuels by oxy-desulfurization. Energy Fuels 23:5986-5994 (2009).

14. Yazu K, Furuya T, Miki K and Ukegawa K, Tungstophosphoric acid-catalyzed oxidative desulfurization of light oil with hydrogen peroxide in a light oil/acetic acid biphasic system. Chem Lett 32:920-921 (2003).

15. Al-Shahrani F, Xiao TC, Llewellyn SA, Barri S, Jiang Z, Shi HH, Martinie $G$ and Green $\mathrm{MLH}$, Desulfurization of diesel via the $\mathrm{H}_{2} \mathrm{O}_{2}$ oxidation of aromatic sulfides to sulfones using a tungstate catalyst. Appl Catal B-Environ 73:311-316 (2007).

16. Yu GX, Lu SX, Chen H and Zhu ZN, Diesel fuel desulfurization with hydrogen peroxide promoted by formic acid and catalyzed by activated carbon. Carbon 43:2285-2294 (2005).

17. Yu GX, Lu SX, Chen H and Zhu ZN, Oxidative desulfurization of diesel fuels with hydrogen peroxide in the presence of activated carbon and formic acid. Energy Fuels 19:447-452 (2005).

18. Zhou X, Tan Q, Yu G, Chen L, Wang J and Novaro O, Removal of dibenzothiophene in diesel oil by oxidation over a promoted activated carbon catalyst. Kinet Catal 50:543549 (2009).

19. Hao L, Shen BX and Zhou XL, An improved desulfurization process based on $\mathrm{H}_{2} \mathrm{O}_{2}$ /formic acid oxidation system followed by liquid-liquid extraction. part 1. Coker gas oil feedstocks. Pet Sci Technol 23:991-999 (2005).

20. Chen LJ, Guo SH and Zhao DS, Oxidative desulfurization of simulated gasoline over metal oxide-loaded molecular sieve. Chin J Chem Eng 15:520-523 (2007).

21. de Souza WF, Guimarães IR, Guerreiro MC and Oliveira LCA, Catalytic oxidation of sulfur and nitrogen compounds from diesel fuel. Appl Catal A-Gen 360:205-209 (2009).

22. Chen LJ, Guo SH and Zhao DS, Oxidation of thiophenes over silica gel in hydrogen peroxide/formic acid system. Chin J Chem Eng 14:835-838 (2006).

23. Deshpande A, Bassi A and Prakash A, Ultrasound-assisted, base-catalyzed oxidation of 4,6-dimethyldibenzothiophene in a biphasic diesel-acetonitrile system. Energy Fuels 19:28-34 (2005).

24. Zhao DS, Ren HW and Li L, Study of oxidative desulfurization of thiophene by phase transfer catalysis. Chem J Chin Univ-Chin 28:739-742 (2007).

25. Zhao D, Ren H, Wang J, Yang $Y$ and Zhao $Y$, Kinetics and mechanism of quaternary ammonium salts as phase-transfer catalysts in the liquid-liquid phase for oxidation of thiophene. Energy Fuels 21:2543-2547 (2007).

26. Murata S, Murata K, Kidena $\mathrm{K}$ and Nomura M, Oxidative desulfurization of diesel fuels by molecular oxygen. Abstr Pap Am Chem Soc 226:U532-U532 (2003).

27. Lu HY, Gao JB, Jiang ZX, Yang YX, Song B and Li C, Oxidative desulfurization of dibenzothiophene with molecular oxygen using emulsion catalysis. Chem Commun: 150-152 (2007).

28. Karas LJ, Han Y-Z and Leyshon DW, Organosulfur oxidation process. US Patent 
2004178122 (2004).

29. Han Y-Z and Leyshon DW, Desulfurization process. US Patent 2005109677 (2005).

30. Karas LJ, Grey RA and Lynch MW, Desulfurization process. US Patent 2008047875 (2008).

31. Kocal JA, Process for the desulfurization of a hydrocarbonaceous oil. US Patent 6277271 (2001).

32. Kocal JA and Branvold TA, Removal of sulfur-containing compounds from liquid hydrocarbon streams. US Patent 6368495 (2002).

33. Wang DH, Qian EWH, Amano H, Okata K, Ishihara A and Kabe T, Oxidative desulfurization of fuel oil - Part I. Oxidation of dibenzothiophenes using tert-butyl hydroperoxide. Appl Catal A-Gen 253:91-99 (2003).

34. Ishihara A, Wang DH, Dumeignil F, Amano H, Qian EWH and Kabe T, Oxidative desulfurization and denitrogenation of a light gas oil using an oxidation/adsorption continuous flow process. Appl Catal A-Gen 279:279-287 (2005).

35. Chica A, Gatti G, Moden B, Marchese L and Iglesia E, Selective catalytic oxidation of organosulfur compounds with tert-butyl hydroperoxide. Chem-Eur J 12:1960-1967 (2006).

36. Zhou XR, Zhao CX, Yang JZ and Zhang SF, Catalytic oxidation of dibenzothiophene using cyclohexanone peroxide. Energy Fuels 21:7-10 (2007).

37. Kuznetsova L, Detusheva L, Kuznetsov N, Duplyakin V and Likholobov V, Liquid-phase oxidation of benzothiophene and dibenzothiophene by cumyl hydroperoxide in the presence of catalysts based on supported metal oxides. Kinet Catal 49:644-652 (2008).

38. Prasad VVDN, Jeong K-E, Chae H-J, Kim C-U and Jeong S-Y, Oxidative desulfurization of 4,6-dimethyl dibenzothiophene and light cycle oil over supported molybdenum oxide catalysts. Catal Commun 9:1966-1969 (2008).

39. González-García $\mathrm{O}$ and Cedeño-Caero L, V-Mo based catalysts for oxidative desulfurization of diesel fuel. Catal Today 148:42-48 (2009).

40. Sharipov A and Nigmatullin V, Finishing of Diesel Fuel to Remove Sulfur Compounds after Hydrotreating. Chem Tech Fuels Oils 41:309-312 (2005).

41. Chica A, Corma A and Domine ME, Catalytic oxidative desulfurization (ODS) of diesel fuel on a continuous fixed-bed reactor. J Catal 242:299-308 (2006).

42. Anisimov A and Tarakanova A, Oxidative desulfurization of hydrocarbon raw materials. Russ J Gen Chem 79:1264-1273 (2009).

43. Campos-Martin JM, Blanco-Brieva $G$ and Fierro JLG, Hydrogen peroxide synthesis: An outlook beyond the anthraquinone process. Angew Chem Int Ed 45:6962 - 6984 (2006).

44. Hirai T, Ogawa K and Komasawa I, Desulfurization process for dibenzothiophenes from light oil by photochemical reaction and liquid-liquid extraction. Ind Eng Chem Res 35:586 (1996).

45. Shiraishi $Y$, Hara H, Hirai $T$ and Komasawa I, A deep desulfurization process for light oil by photosensitized oxidation using a triplet photosensitizer and hydrogen 
peroxide in an oil/water two-phase liquid-liquid extraction system. Ind Eng Chem Res 38:1589-1595 (1999).

46. Hirai $T$, Shiraishi $Y$ and Komasawa I, Desulfurization process for light oil by photochemical reaction and liquid-liquid extraction: Removal of benzothiophenes and alkyl sulfides. J Chem Eng Jpn 30:173 (1997).

47. Hirai T, Shiraishi Y, Ogawa K and Komasawa I, Effect of photosensitizer and hydrogen peroxide on desulfurization of light oil by photochemical reaction and liquid-liquid extraction. Ind Eng Chem Res 36:530 (1997).

48. Borah D, Baruah $M K$ and Haque I, Oxidation of high sulphur coal. Part 2. Desulphurisation of organic sulphur by hydrogen peroxide in presence of metal ions. Fuel 80:1475-1488 (2001).

49. Te $M$, Fairbridge $\mathrm{C}$ and Ring $\mathrm{Z}$, Oxidation reactivities of dibenzothiophenes in polyoxometalate $/ \mathrm{H}_{2} \mathrm{O}_{2}$ and formic acid/ $\mathrm{H}_{2} \mathrm{O}_{2}$ systems. Appl Catal A-Gen 219:267-280 (2001).

50. Yazu K, Yamamoto $\mathrm{Y}$, Furuya $\mathrm{T}$, Miki $\mathrm{K}$ and Ukegawa $\mathrm{K}$, Oxidation of dibenzothiophenes in an organic biphasic system and its application to oxidative desulfurization of light oil. Energy Fuels 15:1535-1536 (2001).

51. Fedorova EV, Zhirkov NP, Tarakanova AV, Ivanov AA, Senyavin VM, Anisimov AV, Tulyakova EV and Surin SA, Oxidative desulfurization of diesel fuel with hydrogen peroxide in the presence of vanadium peroxo complexes. Pet Chem 42:253-256 (2002).

52. Sharipov AK and Nigmatullin VR, Oxidative desulfurization of diesel fuel (a review). Pet Chem 45:371-377 (2005).

53. Zapata B, Pedraza F and Valenzuela MA, Catalyst screening for oxidative desulfurization using hydrogen peroxide. Catal Today 106:219-221 (2005).

54. Lai JL and Luo GX, Oxidation desulfurization of model sulfur compound in the presence of the catalyst of sodium tungstate and sodium hydrogen sulfate. Pet Sci Technol 24:1357-1362 (2006).

55. Mondal S, Hangun-Balkir Y, Alexandrova L, Link D, Howard B, Zandhuis P, Cugini A, Horwitz CP and Collins TJ, Oxidation of sulfur components in diesel fuel using FeTAML (R) catalysts and hydrogen peroxide. Catal Today 116:554-561 (2006).

56. Sharipov A, Nigmatullin V, Nigmatullin I and Zakirov R, Catalytic oxidation of sulfides in middle distillates from medium-sulfur crude. Chem Tech Fuels Oils 42:451-461 (2006).

57. d'Alessandro N, Tonucci L, Bonetti M, Di Deo M, Bressan M and Morvillo A, Oxidation of dibenzothiophene by hydrogen peroxide or monopersulfate and metalsulfophthalocyanine catalysts: an easy access to biphenylsultone or 2-(2'hydroxybiphenyl)sulfonate under mild conditions. New J Chem 27:989-993 (2003).

58. Collins FM, Lucy AR and Sharp C, Oxidative desulphurisation of oils via hydrogen peroxide and heteropolyanion catalysis. J Mol Catal A: Chem 117:397-403 (1997).

59. Mei H, Mei BW and Yen TF, A new method for obtaining ultra-low sulfur diesel fuel via ultrasound assisted oxidative desulfurization. Fuel 82:405-414 (2003).

60. Campos-Martin JM, Capel-Sanchez MC and Fierro JLG, Highly efficient deep 
desulfurization of fuels by chemical oxidation. Green Chem 6:557-562 (2004).

61. Huang D, Wang YJ, Yang LM and Luo GS, Chemical oxidation of dibenzothiophene with a directly combined amphiphilic catalyst for deep desulfurization. Ind Eng Chem Res 45:1880-1885 (2006).

62. Komintarachat $\mathrm{C}$ and Trakarnpruk $\mathrm{W}$, Oxidative desulfurization using polyoxometalates. Ind Eng Chem Res 45:1853-1856 (2006).

63. Etemadi $\mathrm{O}$ and Yen TF, Selective adsorption in ultrasound-assisted oxidative desulfurization process for fuel cell reformer applications. Energy Fuels 21:2250-2257 (2007).

64. Huang D, Zhai Z, Lu YC, Yang LM and Luo GS, Optimization of composition of a directly combined catalyst in dibenzothiophene oxidation for deep desulfurization. Ind Eng Chem Res 46:1447-1451 (2007).

65. Jiang X, Li H, Zhu W, He L, Shu H and Lu J, Deep desulfurization of fuels catalyzed by surfactant-type decatungstates using $\mathrm{H}_{2} \mathrm{O}_{2}$ as oxidant. Fuel 88:431-436 (2009).

66. De Angelis A, Pollesel P, Molinari D, Parker Jr WO, Frattini A, Cavani F, Martins S and Perego C, Heteropolyacids as effective catalysts to obtain zero sulfur diesel. Pure Appl Chem 79:1887-1894 (2007).

67. Li C, Jiang Z, Gao J, Yang Y, Wang S, Tian F, Sun F, Sun X, Ying P and Han C, Ultra-Deep Desulfurization of Diesel: Oxidation with a Recoverable Catalyst Assembled in Emulsion. Chemistry - A European Journal 10:2277-2280 (2004).

68. Lu HY, Gao JB, Jiang ZX, Jing F, Yano YX, Wang $G$ and Li C, Ultra-deep desulfurization of diesel by selective oxidation with $\left[\mathrm{C}_{18} \mathrm{H}_{37} \mathrm{~N}\left(\mathrm{CH}_{3}\right)_{3}\right] 4\left[\mathrm{H}_{2} \mathrm{NaPW}_{10} \mathrm{O}_{36}\right]$ catalyst assembled in emulsion droplets. J Catal 239:369-375 (2006).

69. Huang D, Lu YC, Wang YJ, Yang L and Luo GS, Intensification of catalytic oxidation with a T-junction microchannel reactor for deep desulfurization. Ind Eng Chem Res 47:3870-3875 (2008).

70. Hulea V, Fajula $F$ and Bousquet $J$, Mild oxidation with $\mathrm{H}_{2} \mathrm{O}_{2}$ over Ti-containing molecular sieves - A very efficient method for removing aromatic sulfur compounds from fuels. J Catal 198:179-186 (2001).

71. Shiraishi $\mathrm{Y}$, Hirai $\mathrm{T}$ and Komasawa I, Oxidative desulfurization process for light oil using titanium silicate molecular sieve catalysts. J Chem Eng Jpn 35:1305-1311 (2002).

72. Kong LY, Li G and Wang XS, Mild oxidation of thiophene over TS-1/ $\mathrm{H}_{2} \mathrm{O}_{2}$. Catal Today 93-95:341-345 (2004).

73. Kong LY, Li G and Wang XS, Kinetics and mechanism of liquid-phase oxidation of thiophene over TS-1 using $\mathrm{H}_{2} \mathrm{O}_{2}$ under mild conditions. Catal Lett 92:163-167 (2004).

74. Cheng SF, Liu YM, Gao JB, Wang LL, Liu XL, Gao GH, Wu P and He MY, Catalytic oxidation of benzothiophene and dibenzothiophene in model light oil over Ti-MWW. Chin J Catal 27:547-549 (2006).

75. Cui SH, Ma F and Wang YQ, Oxidative desulfurization of model diesel oil over Ticontaining molecular sieves using hydrogen peroxide. React Kinet Catal Lett 92:155163 (2007). 
76. Wang $Y$, Li G, Wang XS and Jin CZ, Oxidative desulphurization of 4,6dimethyldibenzothiophene with hydrogen peroxide over Ti-HMS. Energy Fuels 21:1415-1419 (2007).

77. Jin C, Li G, Wang $X$, Wang $Y$, Zhao $L$ and Sun D, A titanium containing micro/mesoporous composite and its catalytic performance in oxidative desulfurization. Microporous Mesoporous Mater 111:236-242 (2008).

78. Hulea V, Maciuca A-L, Cojocariu A-M, Ciocan C-E and Dumitriu E, New heterogeneous catalysts for mild oxidation of S-containing organic compounds. Comptes Rendus Chimie 12:723-730 (2009).

79. Jia $Y$, Li G, Ning $G$ and Jin C, The effect of N-containing compounds on oxidative desulphurization of liquid fuel. Catal Today 140:192-196 (2009).

80. Napanang $T$ and Sooknoi $T$, Oxidative extraction of thiophene from $n$-dodecane over TS-1 in continuous process: A model for non-severe sulfur removal from liquid fuels. Catal Commun 11:1-6 (2009).

81. Capel-Sanchez MC, Campos-Martin JM and Fierro JLG, Method for elimination of sulphur from liquid fuels. WO Patent 2009007490 (2009).

82. Shiraishi $Y$, Naito $T$ and Hirai $T$, Vanadosilicate molecular sieve as a catalyst for oxidative desulfurization of light oil. Ind Eng Chem Res 42:6034-6039 (2003).

83. Caero LC, Hernandez E, Pedraza F and Murrieta F, Oxidative desulfurization of synthetic diesel using supported catalysts - Part I. Study of the operation conditions with a vanadium oxide based catalyst. Catal Today 107-08:564-569 (2005).

84. Caero LC, Navarro JF and Gutierrez-Alejandre A, Oxidative desulfurization of synthetic diesel using supported catalysts: Part II. Effect of oxidant and nitrogen-compounds on extraction-oxidation process. Catal Today 116:562-568 (2006).

85. Cedeno-Caero L, Gomez-Bernal H, Fraustro-Cuevas A, Guerra-Gomez HD and CuevasGarcia R, Oxidative desulfurization of synthetic diesel using supported catalysts: Part III. Support effect on vanadium-based catalysts. Catal Today 133-135:244-254 (2008).

86. Gregori F, Nobili I, Bigi F, Maggi R, Predieri G and Sartori G, Selective oxidation of sulfides to sulfoxides and sulfones using $30 \%$ aqueous hydrogen peroxide and silicavanadia catalyst. J Mol Catal A: Chem 286:124-127 (2008).

87. Gómez-Bernal H, Cedeño-Caero L and Gutiérrez-Alejandre A, Liquid phase oxidation of dibenzothiophene with alumina-supported vanadium oxide catalysts: An alternative to deep desulfurization of diesel. Catal Today 142:227 (2009).

88. Yazu K, Furuya T and Miki K, Immobilized tungstophosphoric acid-catalyzed oxidative desulfurization of diesel oil with hydrogen peroxide. J Jpn Pet Inst 46:379-382 (2003).

89. Ramirez-Verduzco LF, Torres-Garcia E, Gomez-Quintana R, Gonzalez-Pena V and Murrieta-Guevara F, Desulfurization of diesel by oxidation/extraction scheme: influence of the extraction solvent. Catal Today 98:289-294 (2004).

90. Torres-Garcia E, Canizal G, Velumani S, Ramirez-Verduzco LF, Murrieta-Guevara F and Ascencio JA, Influence of surface-phenomena in oxidative desulfurization with $\mathrm{WO}_{\mathrm{x}} / \mathrm{ZrO}_{2}$ catalysts. Appl Phys A-Mater Sci Process 79:2037-2040 (2004).

91. Hulea V, Maciuca AL, Fajula F and Dumitriu E, Catalytic oxidation of thiophenes and thioethers with hydrogen peroxide in the presence of W-containing layered double 
hydroxides. Appl Catal A-Gen 313:200-207 (2006).

92. Huang D, Wang YJ, Cui YC and Luo GS, Direct synthesis of mesoporous $\mathrm{TiO}_{2}$ and its catalytic performance in DBT oxidative desulfurization. Microporous Mesoporous Mater 116:378-385 (2008).

93. Rodriguez-Gattorno G, Galano A and Torres-García E, Surface acid-basic properties of $\mathrm{WO}_{\mathrm{x}}-\mathrm{ZrO}_{2}$ and catalytic efficiency in oxidative desulfurization. Appl Catal B-Environ 92:1-8 (2009).

94. Yan X-M, Mei P, Lei J, Mi Y, Xiong $L$ and Guo L, Synthesis and characterization of mesoporous phosphotungstic acid/ $/ \mathrm{TiO}_{2}$ nanocomposite as a novel oxidative desulfurization catalyst. J Mol Catal A: Chem 304:52-57 (2009).

95. Garcia-Gutierrez JL, Fuentes GA, Hernandez-Teran ME, Murrieta F, Navarrete J and Jimenez-Cruz $\mathrm{F}$, Ultra-deep oxidative desulfurization of diesel fuel with $\mathrm{H}_{2} \mathrm{O}_{2}$ catalyzed under mild conditions by polymolybdates supported on $\mathrm{Al}_{2} \mathrm{O}_{3}$. Appl Catal AGen 305:15-20 (2006).

96. Garcia-Gutierrez JL, Fuentes GA, Hernandez-Teran ME, Garcia P, Murrieta-Guevara F and Jimenez-Cruz $F$, Ultra-deep oxidative desulfurization of diesel fuel by the $\mathrm{Mo} / \mathrm{Al}_{2} \mathrm{O}_{3}-\mathrm{H}_{2} \mathrm{O}_{2}$ system: The effect of system parameters on catalytic activity. Appl Catal A-Gen 334:366-373 (2008).

97. Sampanthar JT, Xiao $H$, Dou $H$, Nah TY, Rong $X$ and Kwan WP, A novel oxidative desulfurization process to remove refractory sulfur compounds from diesel fuel. Appl Catal B-Environ 63:85-93 (2006).

98. Kong $\mathrm{LY}$, Li G, Wang $\mathrm{XS}$ and $\mathrm{Wu} B$, Oxidative desulfurization of organic sulfur in gasoline over Ag/TS-1. Energy Fuels 20:896-902 (2006).

99. Si X, Cheng S, Lu Y, Gao G and He M-Y, Oxidative Desulfurization of Model Oil over Au/Ti-MWW. Catal Lett 122:321-324 (2008).

100. Di Giuseppe A, Crucianelli M, De Angelis F, Crestini C and Saladino R, Efficient oxidation of thiophene derivatives with homogeneous and heterogeneous $\mathrm{MTO} / \mathrm{H}_{2} \mathrm{O}_{2}$ systems: A novel approach for, oxidative desulfurization (ODS) of diesel fuel. Appl Catal B-Environ 89:239-245 (2009).

101. Liu D, Gui J, Song L, Zhang $X$ and Sun Z, Deep desulfurization of diesel fuel by extraction with task-specific ionic liquids. Pet Sci Technol 26:973-982 (2008).

102. Huang C, Chen B, Zhang J, Liu Z and Li Y, Desulfurization of Gasoline by Extraction with New lonic Liquids. Energy Fuels 18:1862-1864 (2004).

103. Nie Y, Li C, Sun A, Meng $H$ and Wang Z, Extractive Desulfurization of Gasoline Using Imidazolium-Based Phosphoric lonic Liquids. Energy Fuels 20:2083-2087 (2006).

104. Esser J, Wasserscheid $P$ and Jess A, Deep desulfurization of oil refinery streams by extraction with ionic liquids. Green Chem 6:316-322 (2004).

105. Lu L, Cheng SF, Gao JB, Gao GH and He MY, Deep oxidative desulfurization of fuels catalyzed by ionic liquid in the presence of $\mathrm{H}_{2} \mathrm{O}_{2}$. Energy Fuels 21:383-384 (2007).

106. Zhu WS, Li HM, Hang X, Yan YS, Lu HD and Xia JX, Oxidative desulfurization of fuels catalyzed by peroxotungsten and peroxomolybdenum complexes in ionic liquids. Energy Fuels 21:2514-2516 (2007). 
107. Lissner E, de Souza WF, Ferrera B and Dupont J, Oxidative Desulfurization of Fuels with Task-Specific lonic Liquids. ChemSusChem 2:962-964 (2009).

108. Wang J, Zhao D and Li K, Oxidative desulfurization of dibenzothiophene catalyzed by Bronsted acid ionic liquid. Energy Fuels 23:3831-3834 (2009).

109. Zhao D-s, Sun Z-m, Li F-t and Shan H-d, Optimization of oxidative desulfurization of dibenzothiophene using acidic ionic liquid as catalytic solvent. J Fuel Chem. Technol. 37:194-198 (2009).

110. He L, Li H, Zhu W, Guo J, Jiang X, Lu J and Yan Y, Deep oxidative desulfurization of fuels using peroxophosphomolybdate catalysts in ionic liquids. Ind Eng Chem Res 47:6890-6895 (2008).

111. Zhao DS, Wang JL and Zhou EP, Oxidative desulfurization of diesel fuel using a Bronsted acid room temperature ionic liquid in the presence of $\mathrm{H}_{2} \mathrm{O}_{2}$. Green Chem 9:1219-1222 (2007).

112. Liu D, Gui JZ, Wang L, Zhang XT, Song $L$ and Sun ZL, Study of oxidative desulfurization of diesel catalyzed by acidic ionic liquid. Ranliao Huaxue Xuebao/J Fuel Chem. Technol. 36:601-605 (2008).

113. Wang J, Zhao D and Li K, Oxidative desulfurization of dibenzothiophene catalyzed by Bronsted acid ionic liquid. Energy Fuels 23:3831-3834 (2009).

114. Li FT, Liu RH, Wen JH, Zhao DS, Sun ZM and Liu Y, Desulfurization of dibenzothiophene by chemical oxidation and solvent extraction with $\mathrm{Me}_{3} \mathrm{NCH}_{2} \mathrm{C}_{6} \mathrm{H}_{5} \mathrm{Cl} \cdot 2 \mathrm{ZnCl} 2$ ionic liquid. Green Chem 11:883-888 (2009).

115. Li F, Liu R and Sun Z, Photocatalytic oxidative desulfurization of gasoline by $\mathrm{TiO}_{2}$ in [BMIm] $\mathrm{Cu}_{2} \mathrm{Cl}_{3}$ ionic liquid. China Petroleum Processing and Petrochemical Technology: 53-57 (2008).

116. Zhu W, Li H, Jiang X, Yan Y, Lu J, He L and Xia J, Commercially available molybdic compound-catalyzed ultra-deep desulfurization of fuels in ionic liquids. Green Chem 10:641-646 (2008).

117. Xu D, Zhu W, Li H, Zhang J, Zou F, Shi H and Yan Y, Oxidative Desulfurization of fuels catalyzed by $\mathrm{V}_{2} \mathrm{O}_{5}$ in ionic liquids at room temperature. Energy Fuels 23:5929-5933 (2009).

118. Zhang J, Zhu W, Li H, Jiang $W$, Jiang L, Huang $W$ and Yan $Y$, Deep oxidative desulfurization of fuels by Fenton-like reagent in ionic liquids. Green Chem 11:1801 1807 (2009).

119. Li H, Zhu W, Wang Y, Zhang J, Lu J and Yan Y, Deep oxidative desulfurization of fuels in redox ionic liquids based on iron chloride. Green Chem 11:810-815 (2009).

120. Li H, He L, Lu J, Zhu W, Jiang X, Wang Y and Yan Y, Deep oxidative desulfurization of fuels catalyzed by phosphotungstic acid in ionic liquids at room temperature. Energy Fuels 23:1354-1357 (2009).

121. Li H, Jiang $X$, Zhu W, Lu J, Shu $H$ and Yan Y, Deep oxidative desulfurization of fuel oils catalyzed by decatungstates in the ionic liquid of $\left[\mathrm{Bmim}_{\mathrm{P}} \mathrm{PF}_{6}\right.$. Ind Eng Chem Res 48:9034-9039 (2009).

122. Huaming L, Lining $\mathrm{H}$, Wenshuai $\mathrm{Z}$, Xue J, Yan $\mathrm{W}$ and Yongsheng $\mathrm{Y}$, Deep oxidative desulfurization of fuels catalyzed by phosphotungstic acid in ionic liquids at room 
temperature. Energy Fuels 23:1354-1357 (2009).

123. Lane BS and Burgess K, Metal-catalyzed epoxidations of alkenes with hydrogen peroxide. Chem Rev 103:2457-2474 (2003).

124. Jähnisch $\mathrm{K}$, Hessel $\mathrm{V}$, Löwe $\mathrm{H}$ and Baerns $\mathrm{M}$, Chemistry in microstructured reactors. Angew Chem Int Ed 43:406 - 446 (2004).

125. Kiwi-Minsker $L$ and Renken A, Microstructured reactors for catalytic reactions. Catal Today 110:2-14 (2005).

126. Mello PdA, Duarte FA, Nunes MAG, Alencar MS, Moreira EM, Korn M, Dressler VL and Flores ÉMM, Ultrasound-assisted oxidative process for sulfur removal from petroleum product feedstock. Ultrason Sonochem 16:732-736 (2009).

127. Kertesz MA, Riding the sulfur cycle-metabolism of sulfonates and sulfate esters in Gram-negative bacteria. FEMS Microbiol Rev 24:135-175 (1999).

128. Stoner DL, Wey JE, B. BK and Jolley JG, Modification of water soluble coal-derived products by dibenzothiophene degrading microorganisms. Appl Environ Microbiol 56:2667-2676 (1990).

129. Monticello D, Biodesulfurization and the upgrading of petroleum distillates. Curr Opin Biotechnol 11:540-546 (2000).

130. Kilbane II J, Microbial biocatalyst developments to upgrade fossil fuels. Curr Opin Biotechnol 17:305-314 (2006).

131. Mohebali $\mathrm{G}$ and Andrew BS, Biocatalytic desulfurization (BDS) of petrodiesel fuels. Microbiology 154:2169-2183 (2008).

132. Soleimani M, Bassi A and Margaritis A, Biodesulfurization of refractory organic sulfur compounds in fossil fuels. Biotechnology Advances 25:570-596 (2007).

133. Kodama K, Umehara, K., Shimizu, K., Nakatani, S., Minoda, Y. and Yamada, K., Identification of microbial products from dibenzothiophene and its proposed oxidation pathway. Agric Biol Chem 37:45-50 (1973).

134. Denome S, Stanley, DC, Olson, ES and Young, KD, Metabolism of dibenzothiophene and naphthalene in Pseudomonas strains: complete DNA sequence of an upper naphthalene catabolic pathway. J Bacteriol 175:6890-6901 (1993).

135. van Afferden M, Tappe, D, Beyer, M, Truper, HG and Klein, J, Biochemical mechanisms for the desulphurisation of coal-relevant organic sulphur compounds. Fuel 72:635-643 (1993).

136. Kilbane J, Desulfurization of coal: the microbial solution. Trends Biotechnology 7:97101 (1989).

137. van Afferden M, Schacht S, Klein J and Trüper H, Degradation of dibenzothiophene by Brevibacterium sp. DO. Arch Microbiol 153:324-328 (1990).

138. Kayser KJ CL, Park H-S, Kwak J-H, Kolhatkar A and Kilbane JJ II, Isolation and characterization of a moderate thermophile, Mycobacterium phlei GTIS10, capable of dibenzothiophene desulfurization. Appl Microbiol Biotechnol 59:737-746 (2002).

139. Gray KA MG and Squires $\mathrm{CH}$, Biodesulfurization of fossil fuels. Curr Opin Microbiol 6:229-235 (2003).

140. Watkins LM RR, Schneider D, Broderick R, Cruz M, Chambers R, Ruckman E, Cody M, 
and Mrachko GT, Purification and characterization of the aromatic desulfinase 2-(20hydroxybiphenyl)benzensulfinate desulfinase. Arch Biochem Biophys 415:14-23 (2003).

141. McFarland BL, Biodesulfurization. Curr Opin Microbiol 2:257-264 (1999).

142. Naito M, Kawamoto T, Fujino K, Kobayashi M, Maruhashi K and Tanaka A, Long term repeated biodesulfurization by immobilized Rhodococcus erythropolis KA2-5-1 cells. Appl Microbiol Biotechnol 55:374-378 (2001).

143. Li W, Wang M, Chen H, Chen J and Shi Y, Biodesulfurization of dibenzothiophene by growing cells of Gordonia sp. in batch cultures. Biotechnol Lett 28:1175-1179 (2006).

144. Shennan JL, Microbial attack on sulphur-containing hydrocarbons: implications for the biodesulphurisation of oils and coals. J Chem Technol Biotechnol 67:109-123 (1996).

145. Mohebali G, Ball A, Kaytash A and Rasekh B, Stabilization of water/gas oil emulsions by desulfurizing cells of Gordonia alkanivorans RIPI90A. Microbiology 153:1573-1581 (2007).

146. Chang J, Chang YK, Cho K-S and Chang HN, Desulfurization of model and diesel oils by resting cells of Gordona sp. Biotechnol Lett 22:193-196 (2000).

147. Lee I, Bae H, Ryu H, Cho K and Chang Y, Biocatalytic desulfurization of diesel oil in an air-lift reactor with immobilized Gordonia nitida CYKS1 cells. Biotechnol Prog 21:781785 (2005).

148. Vazquez-Duhalt R, Torres E, Valderrama B and SW LB, Biochemical catalysis impact the petroleum refining industry? Energy Fuels 16:1239-1250 (2002).

149. Kaufman E, Harkins J, Rodriguez M, Tsouris C, Selvaraj P and Murphy S, Development of electro-spray bioreactor for crude oil processing. Fuel Process Technol 52:127-144 (1997).

150. McFarland B, Boron D, Deever W, Meyer J, Johnson A and Atlas R, Biocatalytic sulfur removal from fuels: applicability for producing low sulfur gasoline. Crit Rev Microbiol 24:99-147 (1998). 
a)

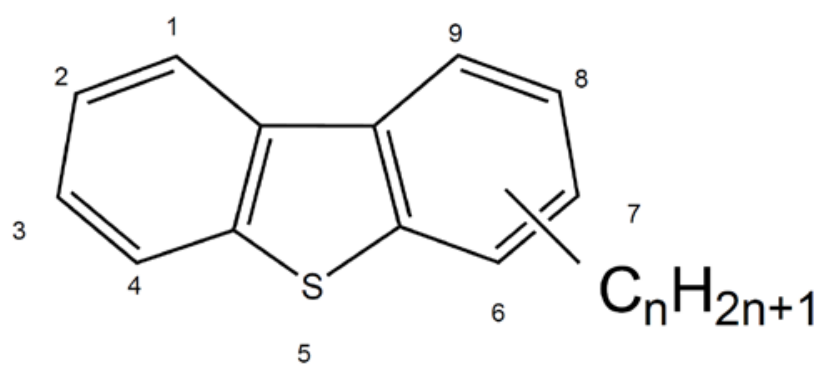

$$
0 \leq \mathrm{n} \leq 6
$$

b)

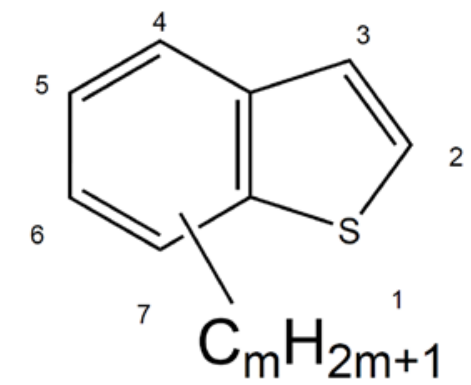

$0 \leq \mathrm{m} \leq 6$

Scheme 1: Structure of DBTs (a), and BTs (b) present in light oils

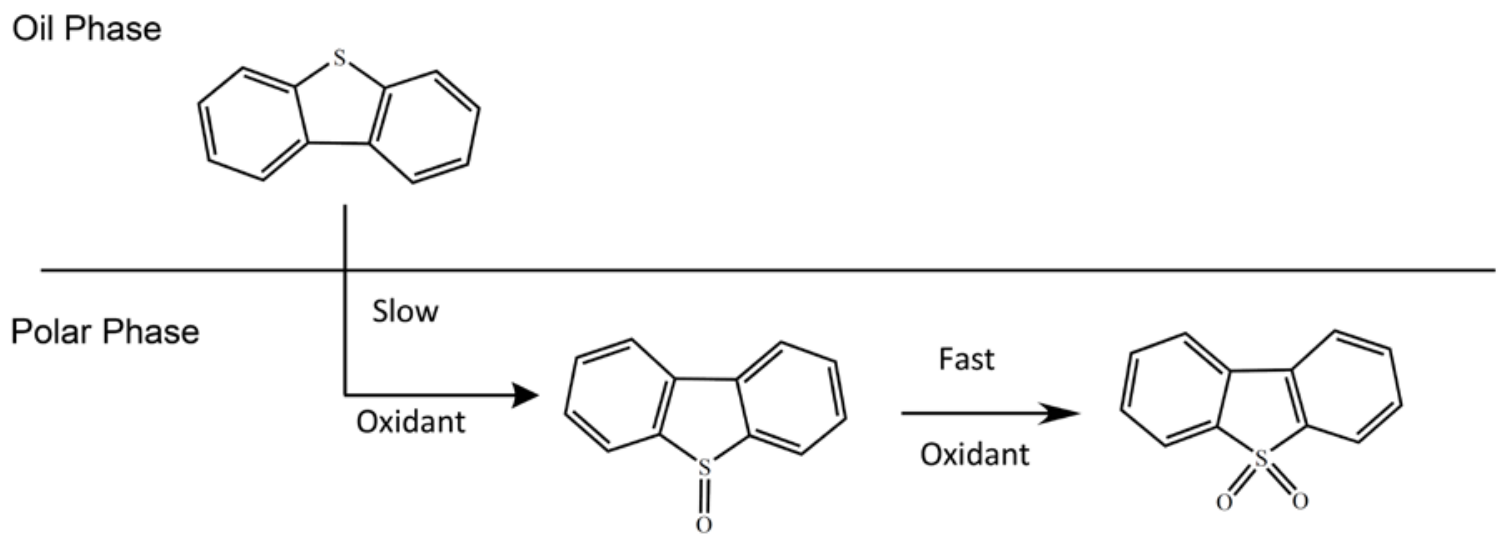

Scheme 2: The ideal reaction in ODS process for DBTs and BTs 


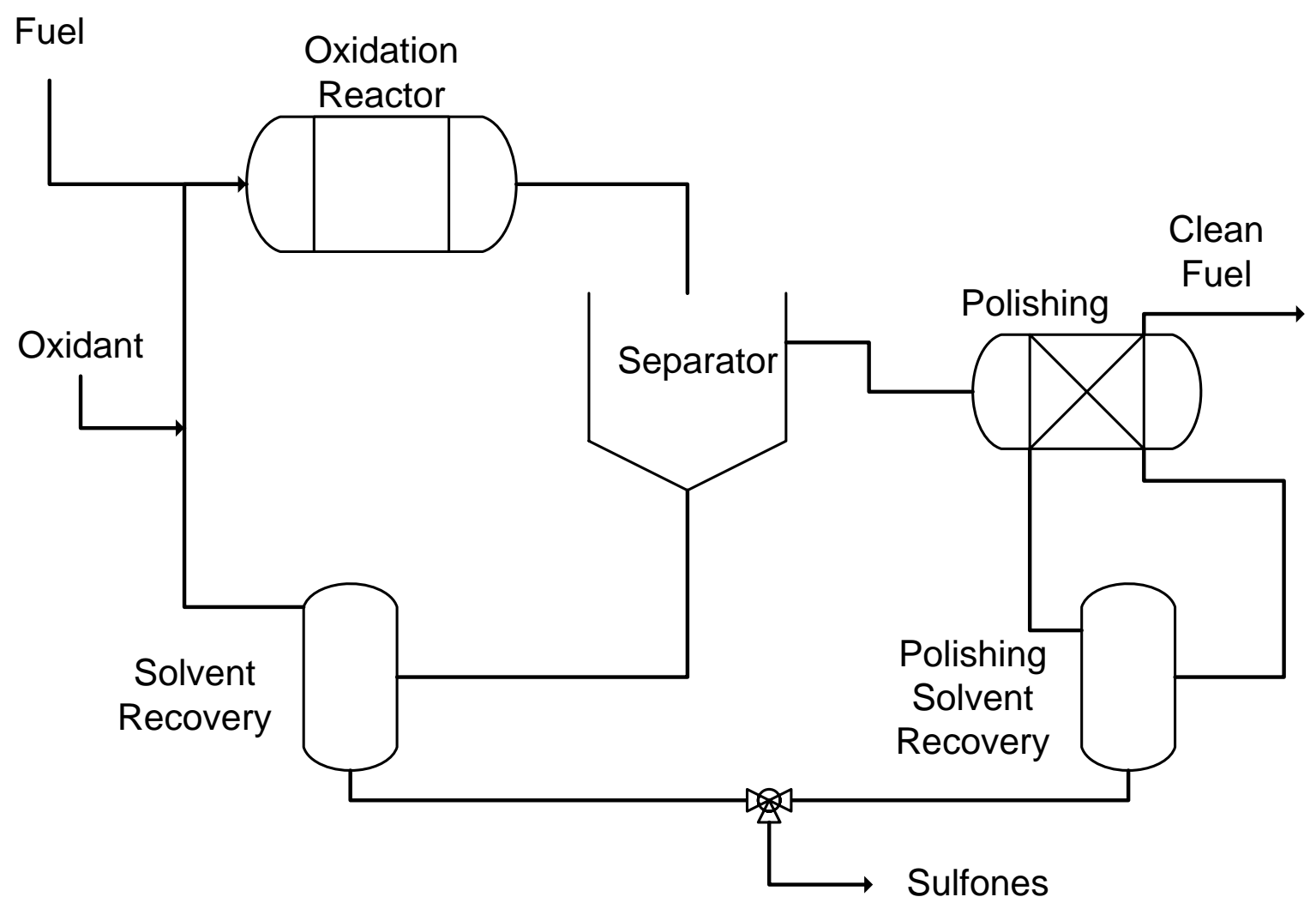

Scheme 3: ODS process. 


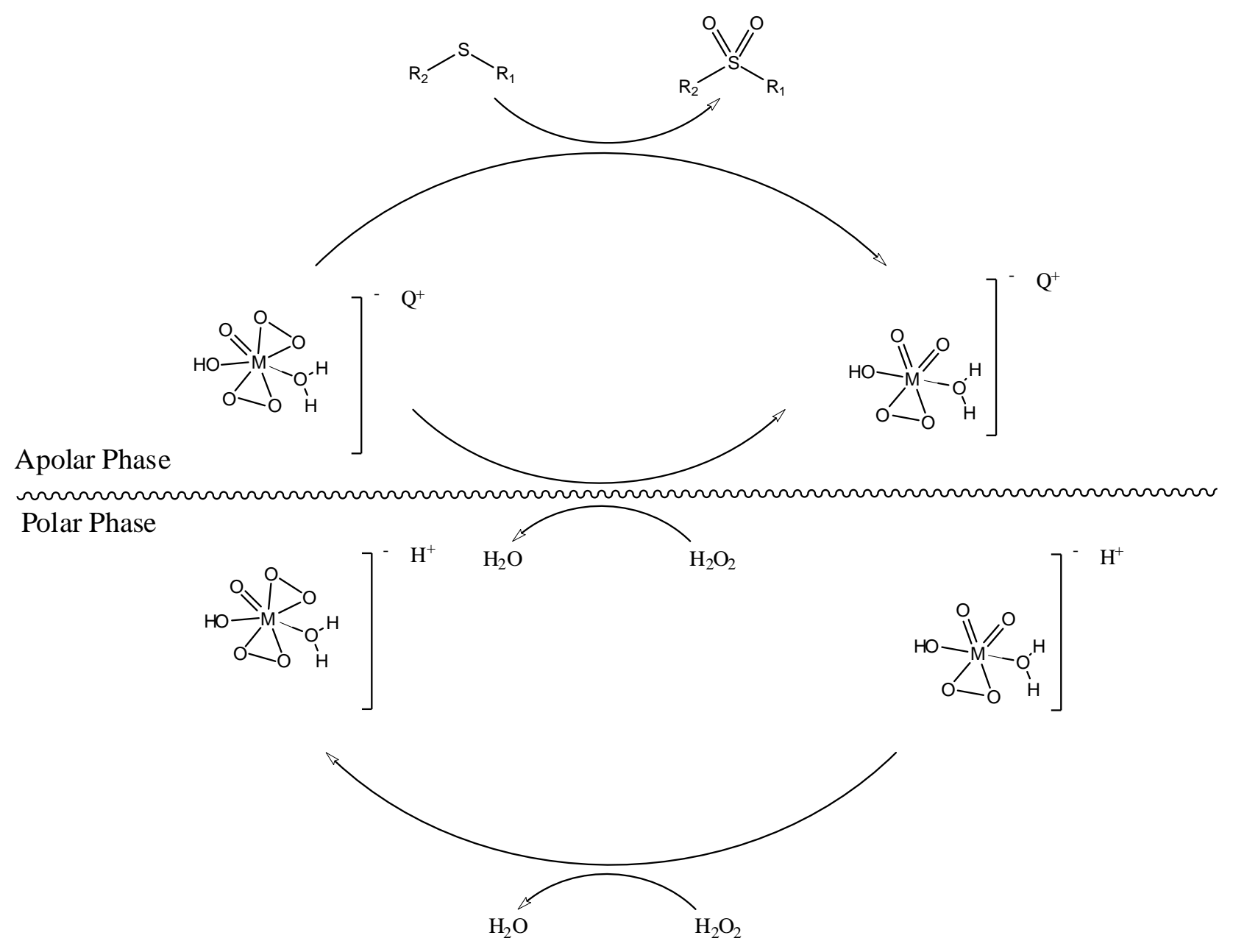

Scheme 4: Catalytic cycle of sulfur compounds oxidation. 
(1)<smiles>c1ccc2c(c1)sc1ccccc12</smiles>

(2)

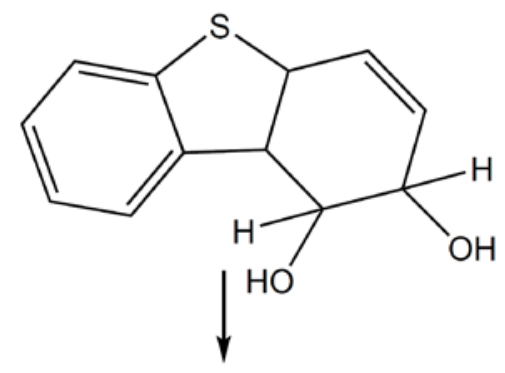

(3)

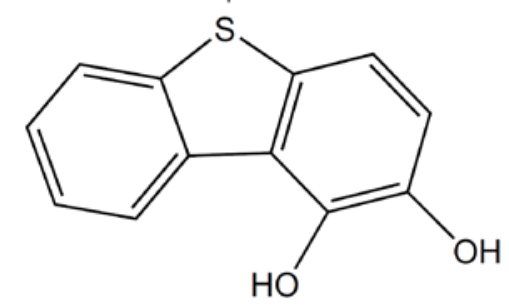

(4)<smiles>[3H][3H]</smiles>

(5)<smiles>O=C(O)C(=O)/C=C/C1Sc2ccccc2C1O</smiles>

(6)<smiles>[3H][3H]</smiles><smiles>O=C(O)C(=O)/C=C/c1sc2ccccc2c1O</smiles>

Scheme 5: Destructive biodesulfurization: Kodama pathway 
DBT
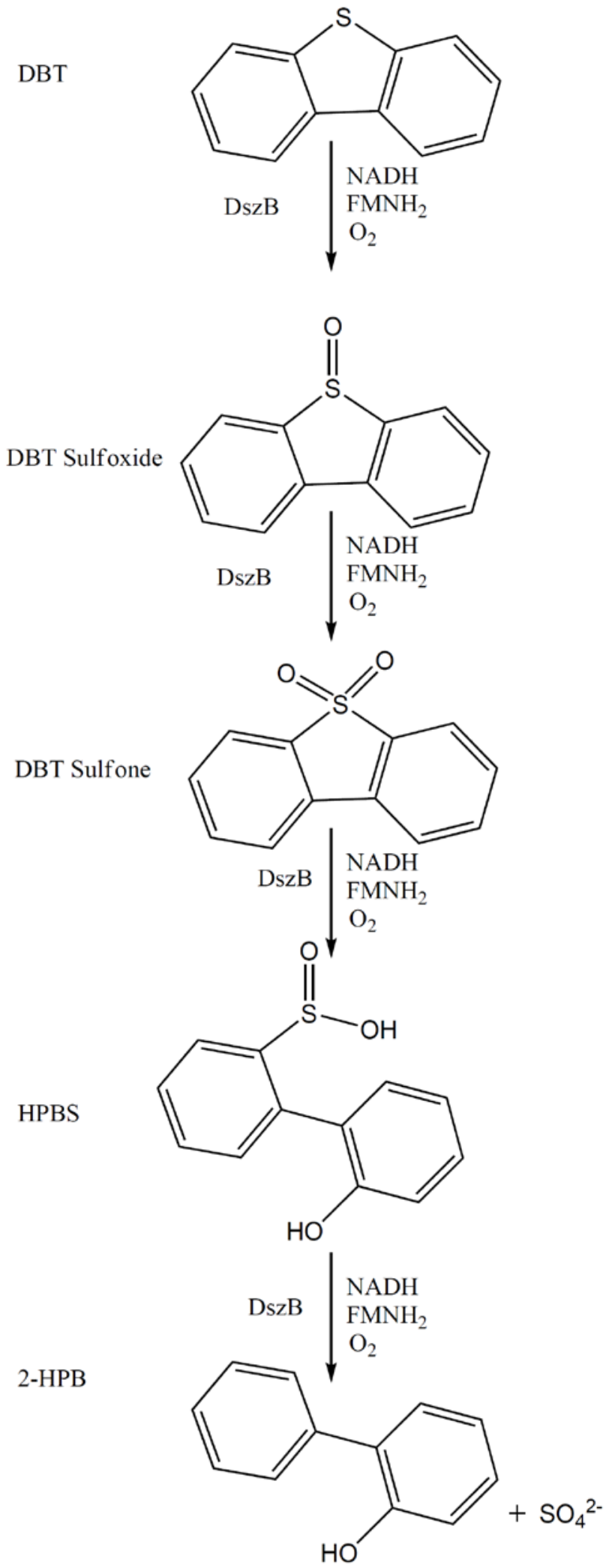

Scheme 6: Specific oxidative biodesulfurization 4s pathway 